\title{
Performative Hybridity of Informal Initiatives Helping Refugees: A Way of Resistance
}

\author{
Mario Rodríguez Polo \& Jaroslav Šotola \\ Palacký University Olomouc, CZECH REPUBLIC \\ Department of Sociology, Andragogy and Cultural Anthropology
}

Received: 4 December 2019 • Accepted: 20 January 2020 • Published Online: 25 January 2020

\begin{abstract}
The so-called "refugee crisis" has challenged establishment putting its capacities under question as the image of a chaotic situation prevailed over European Union and its member states intervention. Formal civil society and big transnational humanitarian institutions also became the target of the critics of a heterogeneous public. Present work argues that current forms of civil engagement, manifested for example in informal initiatives helping refugees, locate their efforts under an umbrella of decolonization of their own societies. Participants in informal initiatives produce with their actions a discourse of outrage, preferentially channelized through direct action approaches, which persecutes the creation of an emancipative alternative. In such a way, participants distance themselves from their societies of origin and came closer to the subaltern groups, such as those under the label "refugees". Informal initiatives participants became, at least figuratively, the new "hybrids" in our society. A group of people figuratively localized between the oppressor forces and the subalterns. Far from essentialist conceptions of hybridity and aware of the critic literature at this respect the concept of hybridity is understood in performative terms. Present study attempts to describe the performance of hybridity by informal initiatives in a context of exercising dialectical power with other social actors, such as authorities as part as the oppressor forces; established civil society which does not seem to really challenge status quo; refugees as a forming subaltern group; and within themselves as part of two worlds full of contradictions and incongruences.
\end{abstract}

Keywords: performative hybridity, informal initiative, refugee crisis, civil society.

\section{Introduction}

During September of 2015 the Czech media generated a fictitious atmosphere of fear under the threat of a "barbarian refugee invasion" that will end with the "honorable European and Christian civilization". Politicians portrayed themselves us protectors keeping citizens safe from the imminent and destructive "migrant wave". Czech Republic was presented as a fortress, defended by police forces at the borders but also in main cities, controlling any suspicious person. Frustrated by the homogeneity of establishment's paranoia small groups arose in main cities organizing help convoys to border corridors and building a solidarity network for those few refugees that exceptionally crossed the country. We followed activist groups in Prague. Action took place in the corridors and main hall of the main train station, one of the most transited and supposedly controlled public spaces in the country. This was a disturbing fact: anti-migrant atmosphere and xenophobic discourses were dominant in Czech society but at the same time,

(C) Authors. Terms and conditions of Creative Commons Attribution 4.0 International (CC BY 4.0) apply. Correspondence: Mario Rodríguez Polo, Palacký University Olomouc, Kř́žžkovského 10, 779 oo Olomouc, CZECH REPUBLIC. E-mail: mario.rodriguez@upol.cz. 
security authorities and state forces at the train station not only tolerated the presence of aid groups but even collaborated with them in a very discrete way. The unrecognized complicity of informal initiatives within authorities allowed refugees to continue their trip. Informal initiatives did not confront the dominant discourses entering in the public arena of discussion, creating public resistance to xenophobic arguments or organizing contra-anti-migrant-demonstrations. Their activism was focused on concrete actions having a direct impact on migrants' destinies thanks to a fragile balance of toleration within authorities. Researchers observed that such incongruences were a pattern characterizing emerging informal initiatives helping refugees all over the Balkan route and then we decided to focus our ethnographic efforts on its understanding (Speed, 2006).

The present work aims to deeply understand a variety of informal initiatives which emerged in Central-Eastern Europe in 2015 as a reaction to the so called "refugee crisis" (Holmes \& Castañeda, 2016; Kallius, Monterescu \& Rajaram, 2016). Their large diversity and constant presence must have called the attention of any witness of the processes of mobility and immobility across the "Balkan route". These groups often acted in liminal areas - such as train stations, borders and border corridors - under the label of "international volunteers". Their name is a declaration of independence against any formal humanitarian actor or state organization. This paper is an attempt to frame their understanding in a transnational arena focusing on the tensions within other social actors: such as NGO's and international humanitarian organizations; the states and some of its structural forces, police and army; and the diversity of actors covered under the common label: "refugees" (Malkki, 1995).

Informal initiatives are not a uniform movement and they show a strong diversity in terms of their size, aims or the intensity or temporality of their existences. It is not our aim to provide a functional typology. Instead, analysis focuses on their ambivalence following a methodological intention to avoid any essentialism. The last is not a statement in favor of a description of an object of study swimming in a postmodern fluidity a la Bauman. Instead our approach is built as a complex mosaic turning around the concept of hybridity, which we believe could provide a rehabilitating view to the social complexity of such interconnected phenomenon. Participants of informal initiatives became, at least figuratively, new "hybrids" in our societies. A group of people figuratively localized between the oppressor forces, the one imposing immobility, and the subaltern, those who attempt to achieve mobility.

The hybridity concept is a fundamental pillar of postcolonial theory and it has been deeply discussed in the last decades (Bhabha, 1994; Young, 2004; Acheraiou, 2011). Hybridity constitutes a key component in the interdisciplinary effort to better understand the unequal relations between colonizers and colonized, claiming that subaltern's identity is not constructed in a clear opposition to hegemony but instead it is constructed through the ambivalent processes of translation and itineration. The concept has been criticized for its lack of uniformity as it may be understood as descriptive (hybridity as méttisage), or normative, remarking subaltern capacity to subvert forms of oppression challenging hegemony not only in a discursive level but also in a practical level. Following Bhabha (1994) resistance forms may be understood as a way to challenge power which does not have to be direct; in its performance may collaborate with power or copy its strategies. A complex understanding of hybridity, as form and strategy (Young, 2004: 345), is inspirational for the understanding of informal initiatives, as even when they clearly oppose to established powers they never combat their dominancy directly. At the same time, our attempt is to frame the so called "migration crisis" as a postcolonial situation in an arena where such approach is not traditional (Lánský, 2014). Refugees are understood as a subaltern entering into the European arena as components of alteration, as they are portrayed as a rupture or a threat to supposed national homogeneities. In our local context, Central-Eastern Europe, the opposition against those searching for mobility hides a hierarchy of unbalanced power structures dominated by privileged European citizens. 
In our study hybridity is not only studied as a component of the postcolonial subjects but it is approached through the hybrid performance of the volunteers groups, which emerged providing basic humanitarian aid across the route. Their hybridity resides in their radical transgression of the discursive limits of us and them, which divides population in deserving and undeserving. Informal initiatives think and act beyond the parameters of any methodological nationalism (Wimmer \& Glick Schiller, 2002,) not only forming groups with aims and actions go beyond the national scope but performing a real transnational agency across borders. Their negation to respect or reproduce physical and discursive borders is a consequence of their unacceptance of established legal inequality on the basis of the nation state and its logics. In such a way, they constitute an opposition to hegemonic conceptions establishing who has the right to live in Europe, who deserves protection or whose mobility must be stopped.

In this work, analysis focuses on the performance of hybridity as a practice. Our methodological decision is also a reaction to the critics targeting the concept, asking for the need to discuss the concept in concrete material and political contexts (Acheraiou, 2011). We propose to work with the term performative hybridity as a way to conceptualize the capacity of this social actor to perform subversive actions, opposing political and economic hegemony and negating constructed binarism of legal citizenship from a radical position. Paradoxically in occasions, intentionally or unintentionally, informal initiative copy and reproduce domination practices. Their hybridity is not understood as a characteristic of a concrete group but as a tactic or strategy responding to a concrete arena, where the practice of hybridity turns to be an advantage. It is our hope to move further with the articulation of this concept from the understanding of informal initiatives helping refugees as simple counter power groups or as temporary forms of civic society. Through the study of their performative hybridity we hope to be able to contribute to the debate of current forms of civic society in Europe and the way to approach future migration challenges. Discussion is located in a network of diverse tensions and positions among present social actors in the field. It is through the study of these tensions in concrete situations where the hybrid character of their agency is manifested. Having this in account the text will analyze the relation of informal initiatives with state authorities, formal NGOs and refugees.

\section{Methodology}

Under the methodological label "informal initiatives" researchers refer to a heterogeneous group of public engagement initiatives which arose as a response to the so called "refugee crisis". Even when such groups manifest a rich diversity attention is located on groups following grassroots logic under a manifested will to establish a horizontal organization, focused on direct action and performing a constructive intention of interaction within other actors that undercover their critical positions (Arditti, 2012).

Researchers have followed these groups to arenas of exercised power - where conflict interactions took place - using multi-sited ethnography as an appropriate tool (Marcus, 1995; Falzon, 2012). The field was physically located on different "non-places" (Augé, 1995), such as 
border corridors ${ }^{1}$, train stations ${ }^{2}$ and other relevant points of the migration route ${ }^{3}$. Such places were strictly controlled by formal authorities as they were the so called "hot spots" where "the crisis" was taken place. Participants of informal initiatives were forced to find a pragmatic way to perform their activities in a very complicated arena where in principle only legitimate state forces and certain civil society actors were supposed to be. Focusing on power and power exercising, and with the help of ethnographic methods, researchers participated and observed how "volunteers" interact within a complex network trying to gain and maintain a legitimate status that allowed them to perform their activities. In the internal fight to solve such difficulties is where hybridity takes place. Power and hybridity are performed through practice so descriptive efforts will try to contextualize and discuss them through field situations.

The research demanded a long term approach, from September 2015 to February 2016, combining peaks of intensive participation and diverse forms of engagement in the field with a continuous monitoring of the initiatives activities. The field proved to be strongly rich in ethnographic materials which were closely analyzed, such as diaries collecting observations and casual conversations on the field, pictures and recorded interviews with initiative participants (Horst, 2015). Engagement with informal initiatives opened us the possibilities to discuss our research with participants of informal initiatives and to carry on in depth interviews with key informants (Hale, 2008). The fact that the emergence and disappearance of informal initiatives occurred ad hoc, as responses to the changing conditions and fast developments which characterized the route during research period turned diachronic approaches into a challenge. Our efforts focused on providing enough information of concrete situations in order to locate analyzed situation on clearly explanatory contexts.

\section{Informal activities and authorities}

\subsection{When restricted areas are not completely restricted}

Informal initiatives are forced to interact with authorities who control the areas where the migration route takes place. Often they may be covered by certain anonymity provided by public spaces when the action is taking place in urban environments such as train stations or squares in their nearby. Municipalities and local authority forces may even find their activities convenient as they solve a social aspect that could easily be pointed as their responsibility. The logic of interactions within authorities must be readapted in areas of border crossings such as corridors or transit facilities. Those areas are usually strictly controlled by authorities and entering in to transit zones is also restricted. At the same time volunteers need to enter in to these areas in order to reach their target, the refugees in need. This situation should be in principle conflictual but reality is that in observed areas volunteers managed not only to enter but even to build aid camps and informal facilities to storage and distribute aid in the restricted areas.

In appearance authorities developed a strict strategy in order to control and limit public engagement in restrictive areas. One of their most common tactics was to request informal camps to join a census of volunteers forcing them to perform their activities under a formalized

\footnotetext{
${ }^{1}$ Paradigmatic is the case of the border closing at Röszke after the Hungarian government completed its fence closing the previous crossing corridors. Researchers were present at the moment the fence was finally closed and an improvised refugee camp arose in the no man's land between Serbia and Hungary on 15 September 2015. Researchers were also able to experience and observe the following corridors: Horgoš (Serbia) - Röszke (Hungary); Berkasovo (Serbia) - Bapska (Croatia); Botovo (Croatia) - Zákány (Hungary); and Hegyeshalom (Hungary) - Nickelsdorf (Austria).

${ }^{2}$ Observation and engagement activities took place in main train stations in Prague, Vienna, Münich and Keleti train station in Budapest.

3 Such as aid storages and logistics centrums controlled by informal initiatives in Vienna and Bratislava.
} 
actor, such as an NGO or an international actor, as for example Red Cross. Volunteers had the obligation to inform from their activities and to formalize their position what could have a strong impact in their previous independency. In practice, the whole situation could be described as chaotic. Authorities were clearly overcome by the situation and could not totally control the transit of refugees, so controlling other actors was secondary. On the other hand, some volunteers stayed on the field maybe only a few days what means that formal procedures were not always possible to accomplish as they took often longer time. Flexibility de facto coexisted within restrictive measures that could be also avoided claiming to "be waiting for documents". In such a way, a restrictive strategy coming from authorities turned to provide a flexible situation where covering tactics allowed volunteers to claim a status of quasi legitimacy.

Not only the presence of volunteers in the area and the construction of camps were tolerated but also the continuous logistic aid convoys crossed across the restrictive areas every day. Almost in a daily basis loaded vehicles crossed the official controls and entered into restricted areas full of food, clothes, blankets and other materials for the camps. Paradoxically - and in contrast with the strict control that governments claimed to have over the so called "hot spots" of the "refugee crisis" - a continuous traffic of vehicles of engaged citizens was taken place in restricted areas without any special permission neither to transport or to distribute goods or food.

Paradoxically, authorities' strict control of the areas turned to be the best legitimacy for the informal camps. Camps were tolerated and legitimated by their activities. For example, authorities controlled hygienic conditions of food storage and had different perspective of activities such as cooking, in occasions allowing volunteers to cook for refuges but also forbidden them to do it. This control was not only restrictive but when positive, it formalized volunteers' position and established clear boundaries of legitimate action for informal initiatives. Paradoxically the camps, as a way of resistance, found legitimacy under the control of establishment forces.

\subsection{Are we enemies? Let's talk about it sharing a coffee or a drink}

It is remarkable that volunteers cultivated and reconfigured their a priori incongruences and ambivalences, such as their opposition to authorities. Different tactics described below help informal initiatives to perform a constructed hybridity which focus was on turning their liminal positions into an advantage. Efforts to get closer to authorities and establish a functional network with other social actors was developed as a tactic on the field. Keeping a good relationship with policemen ensured certain tolerance and flexibility which potentially could facilitate informal initiatives actions. Tactics and approximation behaviors in order to build an arena of mutual trust, and in doing so reinforce collaboration, were embodied in small gestures of everyday life in the conflict areas. For example, at Bapska corridor some policemen got used to drink a morning coffee at the aid camp. Volunteers offered them a hot drink and nice chat. They joked and talked about the difficulties during the night shift. Some officers called volunteer's by their name and shared breakfast break with them. Volunteers read encounters as an opportunity to legitimate their work and earn trust. For authorities was probably also an advantageous situation as they could monitor volunteers camps and activities and keep a direct contact with key volunteers that could become their mediators in case of need. Often locals, who were employed by the municipality to keep the area clean, also joined informal "coffee groups" served by volunteers in front of their tents. During a few minutes the coffee break transformed the transit area in a meeting point for those who stayed and shared the "hot spot" arena day after day. Even when the nature every actor was clearly distant and sometimes in opposition, the morning coffee ritual allowed volunteers to place themselves in a closer and more legitimate position manipulating their hybridity once again in their favor. 
In a similar way but this time during night shifts volunteers' tents received the visit of officers and part of the crew of Red Cross. Volunteers had always ready in a discreet part of their storage a bottle of local spirits and they took turns to have a shot with visitors. One or two shots of palink ${ }^{4}$ kept the bodies warm and gave everyone strength to confront night events. These attitudes extremely informal could be easily criticized and read in moral disapproval. In the field it was interpreted as a way to build a community between the different actors confronting a Dantesque situation. Mutual brotherhood arose from these informal practices and located all actors as part of a common collective. Volunteer's tactic allowed police forces to express their ambivalence as they were not mechanic oppressor but also humans who could empathies with others suffering. The advantage for volunteers is obvious: they found a clear legitimacy; and their presence was now read as the social meeting points where everyone could be a human and not only a police member or part of a bigger organization. Visitors often manifested their frustrations connected to their roles in the refugee crisis. Officers showed their humanity and their empathy within refugees. Policemen often talked about the war, what was also a part of their childhood. They shared their worries about the dangers of such a journey, the sea, bomb attacks, mines, sexual aggressions for women or other abuses during the route as kidnapping or thefts. They shared these thoughts with volunteers that were seen in their eyes as "good people but extremely naïve". With such a discourse they also legitimated their position as authorities. They constructed their image as a strict protection agent, which even when may not show clear sympathy for refugees, is protecting them from the "real" hazards from the route. Distancing themselves from the image of oppressive forces they reconstruct their positions in paternalist approached towards refugees but also towards volunteers 5 . Approaching tactics between social actors lead to the depolarization of their a priori opposite conditions. Mutual alteration is reinterpreted recognizing, even when every actor does it through very different subjectivities, their proximity or belonging to a common position. Previous observations showing hybridity articulations may be framed in Bhabha's described capacities of what he called a Third Space (Bhabha, 1994: 38).

The impact in the field of such a resistance practices was that breaks and informal interactions benefited collaboration when everyone was performing their established roles. As refugee groups were transiting across the volunteers camp friendly officers pointed volunteers their needs with sentences like: "Find some shoes for that kid" or "Don't you have something warm to cover those babies". In another occasion weather forecast announced a big storm for the night. Red Cross received thousands of raincoats but did not have enough personal to distribute them. The solution was to unite forces with their "drinking contacts" among volunteers. Volunteers did not only get access to other organization resources but again they earn legitimacy and their difference with an established civic actor as Red Crossed became blurred in practice. Trust and community experience was also turned into police officers closing their eyes to certain activities that were not allowed to volunteers but were morally legitimated, such as regrouping families in order that they could travel in the same bus to next transit location; finding medical help in case of need; and even allowing them to exceptionally transport in their vans people in need. At the same time, proximity with authorities opened the possibility of new forms of resistance on the basis of flexibility between obedience and disobedience. Volunteers gained some possibility not to fully or immediately fulfil authorities orders such as keeping the lines or showing certain laziness to accomplish police mandates when were in opposition with their principles. Forms of resistance were articulated in a context where opposition and conflict were conducted to certain collaboration. But this situation was clearly unstable and as we describe below was not free of tensions.

\footnotetext{
${ }^{4}$ Local spirits.

5 Similar paternalistic approaches have been observed by author when presenting their research on informal activities to political actors interested on civil society approaches towards refugees.
} 


\subsection{When the volunteer's body becomes the meeting point of two worlds in conflict}

A clear example of how volunteers embody the tensions between authorities and refuges could be found in the following field experience. During our stay at Bapska corridor police forces changed again their people. Through the volunteers a rumor spread saying that policemen were becoming too weak. It seems that the origin of previous policemen, who came from nearest areas to Bapska corridor, which was one of the most affected areas during the Balkan war, played a big role in their growing empathy towards refugees. Empathy and solidarity towards refugees constituted a problem for them at the time to fulfill orders. The rumor was pictured with powerful scenes claiming that some volunteers spotted policemen crying at the corridor. Being the rumor true or not, during the night new and unknown authorities were on the field and previous power balance did not apply anymore. The new policemen were aggressive and rude. They continuously shout orders to the refugees and limited the areas of action and time capacity of the volunteers. They even did not allow groups of refugees to stop at the aid camp to take water, food or clothes. Volunteers tried to mediate with officers. Their response was arbitrary; some of them became a little bit more flexible allowing refugees to briefly stop at the camp, while others kept marching showing clear opposition to volunteers. Volunteers discussed the possibilities of action: should they respect the new-status quo and try a long term strategy patiently earning a friendlier environment; or should they openly oppose police behavior and risk the camp existence and good relations with some of the establishment members. This was a powerful dilemma. While discussion between volunteers was taking place inside the tents, outside groups of refugees kept crossing the corridor under the demeaning yells and shouts of some of the officers. It was time to take a decision in order to solve the dilemma as soon as possible. The consensual strategy decided not to confront aggressive officers when they did not allow refugees to stop by the camp but instead take alternative action. From one side volunteers from the "clothes" area will rapidly monitored extreme needs, as people without shoes or children without warm clothes. Then they will just run and provide aid "on the move". Another volunteer will welcome the group and escort it through the corridor. His or her role will be to calm the situation providing information and speaking in a friendly way to refugees. In practice, having someone identified with the reflective vest located between the officer and the group soon calm the situation. Officers were not so free to yell at the groups and even when they do it the volunteer offered his counter discourse. At the same time any abuse from the part of authorities will be immediately reported by the volunteer. The volunteer would also try to avoid situations that potentially could increase the nervousness of authorities, such as fragmentation of the group or the separation of some of the group members. Also volunteers slightly tried to keep the order of two lines ${ }^{6}$ that was also appreciated by officers as it fits their para-military criteria of order. In doing so the officer also got something from volunteer's collaboration and the tensions tend to low. Walking through the corridor the hybrid body of the volunteer became a barrier protecting refugees and controlling authorities' agency. With the only help of a reflective vest and a friendly discourse volunteers inverted the logic of fear created by new police forces into certain equilibrium under the parameters of humanitarian action. Their corporal position serves also as an example of their liminal condition in between the two worlds embodied in establishment forces - as the embodiment or at least performer of establishment oppression, and refugees - as subaltern.

\footnotetext{
${ }^{6}$ Establishment forces tent to organized transit refugees into groups of 50 or 60 people ordering them to march into two parallel lines. Volunteers usually did not clearly collaborate with this practice, as in their understanding, its martial nature constituted a tension towards scared refugees who were treated as prisoners.
} 


\subsection{Tricking male hierarchies}

In a similar way another paradox affects articulations of hierarchy in the camps. Even when the ideology and practice of most of the studied camps claimed a strong preference for nonhierarchical horizontality a figure of a "coordinator" often emerged as a link to the outside world. In occasions a member of the camp acted as a reference person for authorities in other to mediate and communicate with the camp. The "coordinator" could also act as a reference person for newcomers joining the camp. For example in Bapska camp at the time of our research a young Swiss girl was often pointed by volunteers as the contact person for newcomers, and she also was requested by authorities when they needed to communicate with volunteers. She had been the longest time at the camp so was understood as a leading continuity by authorities and at the same time her knowledge and experience was respected by new volunteers. It is interesting to notice that her leadership based on her continuity and experience was not something that she easily accepted. She refused to be addressed as coordinator and always explained her preference for horizontal approaches to everyone who just arrived. She refused to take her own decisions neither command tasks to do. Even when she was recognized as a legitimate "leader" of the camp, the own internal logic of power erased any possibility of leadership. At the same time she accepted temporal functions of representation in order to maintain a constructive relationship with the authorities, using the hybrid mask of coordinator in front of the others. Her power is again in our understanding an embodiment of hybridity as is born in an internal contradiction between the "world" of the camps and the "world" of formal authorities. Two worlds forced to meet and manipulated by volunteers in such a way that conflict and opposition are turned into compromises allowing them to transform both realities. In this case there is a clear intention to perform their hybridity on their favor even when a priori they are admitting a compromise against their own logic.

The feminist glasses of any social researcher will certainly remark the carnivalesque character of previous leadership compromise. It is true that the informal initiatives compromised to accept the imposition of a representative coordinator but in many cases this coordinator where young female activists. An observation repeated on the field, a young female coordinator discussing, negotiating, making compromises, with always male army authorities or male police officers. Gender contradictions should be remarked as informal initiatives deeply contra posed the patriarchal limits of our societies. Female activists' empowerment found not clear gender barriers in a social situation opposing the established logics of society. As a consequence young girls performed highly responsibility or representative positions even interacting within one of the most masculinized areas of current societies, the army.

It must be remarked that even when volunteers may manage on the field to establish a functional collaboration with authorities, solid boundaries are also kept between them. One of these limits is the access to information. In occasions authorities did not share information about the expected number or refugees arriving to the area neither informed of the official plans and perspectives. Such a lack of transparency forced volunteer work to be a continuous improvisation in a context of uncertainty and information chaos. Hence, it is difficult to balance interaction with authorities as they were always in a changing context or circumstantial tensions. In a formal level tensions kept an unstable equilibrium between tolerance and legitimate recognition. In informal levels tensions were embodied in dense social networks of personal interactions under a chaotic situation that overcome all present social actors.

\section{Interactions with formal civil society}

Informal initiatives constitute a form of public engagement constructed until certain extent in opposition to common organized civil society actors, such as NGO's or transnational human rights organizations (Harell-Bond, 2002). With a strong preference for independent and 
self-organizing systems informal initiatives negate the role of mediator between "subalterns in need" and "public" whose agency is limited to founding of supporting NGOs projects. Such tendency is motivated by a worldview understanding formal actors of civil society as part of the establishment. Inefficiency of established civil agents was confirmed in the eyes of volunteers with their incapacity to confront the humanitarian disaster taking place under the label of "refugee crisis". A parallel could be established with Nandy's cruel label for elite nationalists as "ornamental dissenter's (Young, 2004: 344, quoting Nandy, 1983: xiv). In terms of meanings and selfidentification informal initiatives distance themselves from organized civil society and try to approach to the subaltern. A participant put it in the following words: "Let's do something real". Is this symbolic dislocation what transformed them in society hybrids as their position is characterized by the incongruences and inconsistences of their refusal to the "world" they previously belong and their search for a new position a more active roles in the alternative their initiatives perform.

Disaffection to their previous environment is clearly manifested for example in a strong attitude of no-label politics7. Informal initiatives avoid clear definitions or any other construct that could turn them in an essentialist version of themselves putting them again under the logic of establishment forces.

\subsection{Acting under the cover of a formal actor}

The complexity of the field forced informal initiatives to act covered under a formal civil organization. Such was the case of a group of volunteers connected to SOS Röszke ${ }^{8}$ providing aid to refugees inside the Opatovac transit facilities. Opatovac facilities, under strict military control, received refugees who came directly by bus after crossing the Bapska corridor. There, they had to wait an uncertain time (could be a few hours or one or two days) to continue their journey taking a train to Botovo, at the border with Hungary. The area was controlled by the army and only formal humanitarian entities such as Red Cross or Doctors without Borders were allowed to enter in the camp. Informal volunteers managed to establish a collaboration under Red Cross thanks to a personal relationship with a "functional coordinator" from the informal initiative and the person in charged at the local Red Cross. The collaboration allowed informal volunteers to go through a bureaucratic process of registration which gave them entrance into the very restricted area. This strategy allowed them to have a permanent storage inside the military camp, which was regularly supplied by informal donations, and a tent with tens of plugs for charge mobile phones. The access to the camp was used also by an independent volunteer who used the cover of Red Cross to install an independent WiFi Point inside the restricted area. As the tent in the camp was relatively small, and volunteers were not allowed to enter into the camp with their vehicles, an informal camp emerged next to the transit facilities. In a next field, informal volunteers established their camping tents to spend the nights and also big tents serving for storage for clothes, mostly coming from Austria that will be distributed inside the camp. Improvised headquarters served as the same time as communal kitchen for volunteers and logistic center. Several white boards organized in a horizontal way: distribution of shifts for tasks inside the camp; logistics; and their own transport in cars coming from and leaving to Austria or Germany. Other tasks, such as treading and organizing clothes in the storages were taken voluntarily without any formal mediation. In doing so, the informal initiatives adapted its nature to two very different logics being able on the one hand to cope under the restrictive bureaucratic military regime inside the transit camp, and in the other hand keeping their liberty of engagement of their members and their horizontal strategies. More than a contradiction, observations are again an embodiment of their hybrid condition which

\footnotetext{
7 A paradigmatic example may be found in Vienna's train station were members of organized social actors, such as Red Cross or other established NGOs, should cover the logos in their clothes and vests with adhesive tape as a requirement imposed by informal initiatives acting in the area.

8 SOS Röszke, see at https://www.facebook.com/events/898993260182425/, accessed 13 September 2015.
} 
is performed always in adaptation to tactics and strategies on the field. The relation with Red Cross was just a formal requirement that allowed volunteers to build an informal camp next to the military facilities in principle covered by the legitimacy of the Red Cross.

\subsection{Tensions and conflicts with formal civil society}

Interactions with formalized actors conforming civil society is not aware of tensions and conflicts. During the field researchers could engage in situations where both actors needed each other and were forced to join forces. An illustrative example could be a short sketch from the chaotic days of middle September 2015 at an improvised refugee camp which emerged after the completion of Hungarian plot closing a previous corridor between Serbia and Hungary. Thousands of refugees got stocked in their way in an area without any infrastructure. Informal initiatives and independent volunteers rapidly established a camp offering medical aid and distributing food, clothes and drinking water. Soon, formal actors were also present in the area. During the first days there was a lack of drinking water in the area. In one or two days water tanks will be provided by civil society organizations alleviating basic needs but in the while a solution was needed. A small team from a Central Eastern European NGO present in the first hours had the capacity to pay for water pallets. But they did not count with a way to transport it, neither counted with the human resources necessary to distribute the water in such a chaotic situation. In a public volunteers assembly NGO workers asked for potential help to independent volunteers. Their vans could provide the transport and they could do the distribution walking across the occupied fields with tents and improvised camps. The collaboration was established but the two actors soon entered into conflict.

Driving back to the field she [the NGO's leader] started to do some confidences about her feelings about the buying water action and collaboration with independent volunteers. She was very upset after buying the water because it was not an efficient action. She was completely right but thanks to the volunteers they could manage to do something that they have no options before. They had the money but they needed people and transports. She was also annoyed because the other van [meaning a group of volunteers who provided their logistic capacity] expressed their willing to start distributing water by their own [meaning not under the NGO commands]. She wanted to keep the water in the storage and control the distribution process. She claimed: It is OUR water. We PAID for it.

Rodríguez's fieldnotes, Röszke, 15 September 2015.

Volunteers understood the situation in terms of cooperation among equals and demanded a strong respect for everyone's independency. The NGO leader understood the situation as a benefit for her and she presupposed a superior hierarchical role over volunteers based in NGO's professionalism and economic capacity. The narration of this conflict attempts to exemplify the different perspective of both actors. Even when volunteers, and until certain extent also NGO members, were able to perform their hybrid condition in mutual terms their alterations emerged creating opposition. Volunteers reinforced their liminal position defending their independency while the NGO leader expected to maintain their dominant position. Even where both actors where a priori in close proximity and shared very similar goals their approaches were so different that the alteration between them kept growing into an escalating tension.

\section{Interactions with refugees}

\subsection{Reinforcing their subaltern condition}

In the previous narratives is remarkable the absence of agency or even the lack of presence as subjects of refugees. Interactions with the diverse category covered under the label 
"refugee" were radically subjected to the circumstances under which the encounter took place. Often the nature of the interaction was limited by extreme temporal limitations. An example is the walking corridors where refugees nearly did not have time to stop in the camp aid, they rapidly took what they needed and continued. In other places such as train station or transit areas the interaction could get more complex as it had the opportunity to be prolonged on time. Field observations will explore one of the biggest challenges confronted by informal initiatives which deeply arose from their ambivalence and hybrid condition: how to interact within refugees in order not to reproduce establishment colonialist approaches.

Researchers could observe and participate in several public assemblies which took place during the mid-September events at Röszke. Assemblies were introduced as the main instrument to organized independent volunteers and to design their interaction within authorities, formal civil society actors and refugees. Their approach towards refugees was clearly noninclusive. Starting with the fact that were no refugees present in the assembly. Other actors, as NGO's workers, joined and unified forces with the informal agents. Current analyses points to the emergence of a colonialist dilemma (Long, 2013). Volunteers were distancing themselves from their target group. In such a way, they were constructing a differentiation between "those able to help" and "those who need help"; those who have agency and those who are mere objects. Certainly such a difference was not aware of contradictions. Some volunteers pointed the potential benefit of increasing their working capacities if they extent their agency to refugees. But still them, this argumentation hides an opportunistic approach objectivizing refugees as labor force to be used or commanded. The language skills of some of the refugees qualified them as valuable translators, and in doing so, as potential mediators between volunteers and the refugees. Another task pointed as requiring external labor force was garbage collection, in order ensuring certain hygienic conditions. It is remarkable that potential refugee agency was understood under the planning or commands of the volunteers what constitutes a contradiction with their claimed independency and self-organization, basic characteristics in the construction of informal initiatives. A clear embodiment was observed in the space where the assembly took place, which also served as storage. The area was limited by a cordon, separating the "refugee areas" from the "volunteers' headquarters". Refugees were not expected to cross the cordon neither to take part of decision making processes. They were transformed in an "object" which received help or which was considered useful as "translation tools" that could provide mediation between volunteers and the "others". In doing so, informal initiatives reinforced the condition of refugees as a subaltern. Such incongruences are characteristic for hybrid actors who even when their efforts search the emancipation from subjugating powers are not always able to avoid its reproduction.

\subsection{When mimicry is turned into sarcasm}

A final observation reinforces the articulation of the hybrid condition of volunteers and the strong incongruence embodied in their own nature. In the housing facilities of Gabčíkovo ${ }^{9}$ provided and controlled by Slovak Government in collaboration with Austrian authorities researchers were surprised to meet young guys wearing vests and acting as mediators within refugees and authorities. The profile seemed to fit in what our research efforts was trying to define as "independent volunteers" or "members of an informal initiatives". To our surprise they were employed by the Slovak Interior Ministry as mediators or social workers. They were the bridge between authorities and refugees but clearly subjected to authorities program. It is remarkable that the dominant forces adopted the image of the volunteer providing their workers with "nolabel" vests. It is a clear embodiment of the hybridity of the volunteer figure: a friendly power located in the liminality between the two worlds. In this case, establishment managed to

\footnotetext{
${ }^{9}$ In July 2015 the Slovak Government - based on a bilateral agreement signed with the Austrian ministry of Interior - agreed to temporarily house in the town of Gabčikovo near the Hungarian border around 500 refugees.
} 
manipulate the meaning of the hybrid component and benefited from its symbolic half-way position. The situation reminds the descriptions of mimicry where the colonized attempts to imitate colonizer modes and behaviors but always the result is somehow comic and demeaning. In our case the situation turned into sarcasm as establishment capitalized the powerful image of the independent volunteer on its favor.

\section{Conclusions}

During the last decade life among European societies have become an art of surviving continuous crisis. The so called "refugee crisis" seems to have reinforce embodiments and ways of resistance of certain parts of local population who construct themselves in clear opposition to establishment's hegemony. Understanding the heterogeneous group under the label "refugee" as subaltern, critical forms of public engagement organized in what authors propose to call informal initiatives. Their main aim was to provide aid to refugees across very diverse spots of the so called Balkan route. Through a series of multi-site fieldworks and engagement, authors gain ethnographic knowledge about informal activities and their interactions with other social actors in the field. Informal initiatives are constructed in opposition to hegemonic values but in their performance are not aware of incongruences and ambivalences. Performance hybridity characterizing informal initiatives is performed through their agency focused on helping refugees. Their actions as they oppose establishment and confront it in their performance are understood as a way of resistance. Through ethnographic efforts authors tried to describe and interpret the way the hybridity of informal initiative is performed towards three different social actors: establishment forces as an articulation of establishment oppression; civil society characterized by certain "ornamental dissenter" position; and finally towards refugees as a subaltern.

Informal initiatives manipulate their hybridity and ambivalence developing tactics to be able to carry their help activities on the field. Even in occasions, complex strategies arose benefiting from their knowledge as insiders of the social reality they are opposing. Emerging ways of resistance may even challenge the deep structures of European societies. Participants do not enter in dialectical opposition with public arena but discreetly build an alternative reality for their activities. With their action they reconstruct their ambivalence as a tactic. Such alternative approach to refugees and interaction within them do not only oppose to the political or societal approaches to the so called "migration crisis" - they are performing acts of dissidence closed to civil disobedience. With their actions informal initiatives confront the established limits of the deserving solidarity group formed under a nation-state paradigm and spreading it to a universal framework (Yarris \& Castañeda, 2015). As a consequence of this fact and remarking their inclusive approach to refugees informal initiatives also negate the dominant social construction of migrants as main figures and holders of alteration. Their preference for direct action may also challenge current paradigms of who has the possibility to implement any social agency. Agency in social affairs is currently stressed as a state or politician capacities, complemented or corrected by established social society but is not expected to be implemented by normal citizens. Negation of representative actors generates an estrangement between informal initiatives and formal civil society actor that a priori share similar interests. The solidarity agency and confrontation agency to injustice seems to be dislocated from the established civil society spectrum. Informal initiatives, in their continuous stress of independent agency and inclusive equality, confront also gender inequality and in doing so the basic pillars of patriarchy. The sum of such oppositions and ways of resistance turned informal initiatives into a transformative actor in similar way as last European social movements (della Porta \& Diani, 2006; Badiou, 2012).

Observations on the field described how the performance of their hybridity may turn into empowerment and legitimacy. A preference to create dense social networks within other social actors is used to cover their conflic opposition tending to create collaboration areas. Inequality of agency possibilities and previous constructed approaches towards the "other" may 
also turned their hybrid condition in embodiments that in contradiction to their principles reproduce or reinforce criticized establishment's values. Their legitimacy and recognition by refugees may also be manipulated by other social actors as in the case of Gabčikovo. The question for the future is until which point informal initiatives helping refuges, understood as a way of resistance, could go beyond the "refugee crisis" and have a transformative impact in European societies.

\section{Acknowledgements}

The research was conducted with the support of the Czech Ministry of Education, Youth and Sports, grant project IGA_FF_2014_056.

The authors declare no competing interests.

\section{References}

Acheraiou, A. (2011). Questioning hybridity, postcolonialism and globalization. London: Palgrave Macmillan.

Arditti, B. (2012). Insurgencies don't have a plan - they are the plan: Political performatives and vanishing mediators in 2011. Journalism, Media and Cultural Studies, 1, 1-16.

Augé, M. (1995). Non-places. Introduction to an anthropology of supermodernity. London: Verso.

Badiou, A. (2012). The rebirth of history - Times of riots and uprising. London: Verso.

Bhabha, H. K. (1994). The location of culture. London: Routledge.

della Porta, D., \& Diani, M. (2006). Social movements: An introduction. $2^{\text {nd }}$ ed. Oxford: Blackwell. First published 1999.

Falzon, M.-A. (2012). Multi-sited ethnography: Theory, praxis and locality in contemporary research. Farnham: Ashgate.

Hale, Ch. (2008). Engaging contradictions: Theory, politics, and methods of activist scholarship. Berkeley: University of California Press.

Harrell-Bond, B. E. (2002). Can humanitarian work with refugees be humane? Human Rights Quarterly, 24(1), 51-85.

Holmes, S. M., \& Castañeda, H. (2016). Representing the 'European Refugee Crisis' in Germany and beyond: Deservingness and difference, life and death. American Ethnologist, 43(1), 12-24.

Horst, H. A. (2015). Being in fieldwork: Collaboration, digital media and ethnographic practice. In: R. Sanjek \& S. Tratne (Eds.), eFieldnotes: The makings of anthropology in a digital world (153-168). Philadelphia: University of Pennsylvania Press.

Kallius, A., Monterescu, D., \& Rajaram, P. K. (2016). Immobilizing Mobility: Border ethnography, illiberal democracy, and the politics of the 'refugee crisis' in Hungary. American Ethnologist, 43(1), 2537.

Lánský, O. (2014). Postkolonialismus a dekolonizace: Základní vymezení a inspirace pro sociální vědy. Sociální studia, 11(1), 41-60.

Long, K. (2013). When refugees stopped being migrants: Movement, labour and humanitarian protection. Migration Studies, 1(1), 4-26. 
M. R. Polo \& J. Šotola - Performative Hybridity of Informal Initiatives Helping Refugees: ...

Malkki, L. H. (1995). Refugees and exile: From 'refugee studies' to the national order of things. Annual Review of Anthropology, 24, 495-523.

Marcus, G. E. (1995). Ethnography in/of the world system: The emergence of multi-sited ethnography. Annual Review of Anthropology, 24, 95-117.

Speed, Sh. (2006). At the crossroads of human rights and anthropology: Toward a critically engaged activist research. American Anthropologist, 108(1), 66-76.

Wimmer, A., \& Glick Schiller, N. (2002). Methodological nationalism and beyond: Nation-state building, migration and the social sciences. Global Networks, 2(4), 301-34.

Yarris, K., \& Castañeda, H. (2015). Discourses of displacement and deservingness: Interrogating distinctions between 'economic' and 'forced' migration. International Migration, 53(3), 64-69.

Young, R. J. C. (2004). Postcolonialism. An historical introduction. $2^{\text {nd }}$ ed. Oxford: Blackwell Publishers. 